\title{
01.1;04.1
}

\section{Динамическая модель подводного разряда}

\author{
(c) А.В. Хлюстова
}

Институт химии растворов им. Г.А. Крестова РАН, Иваново, Россия

E-mail: kav@isc-ras.ru

Поступило в Редакцию 25 мая 2021 г.

В окончательной редакции 21 июня 2021 r.

Принято к публикации 28 июня 2021 г.

\begin{abstract}
Представлена динамическая модель подводного электрического разряда. В основе метода лежит математическое описание зависимости проводимости слоя раствора от его толщины в процессе формирования парогазового пузыря, в котором возникает разряд. С помощью выражений, связывающих ток и напряжение с сопротивлением (проводимостью) раствора, и с учетом периодичности процессов рассчитаны временны́е зависимости тока в цепи и падения напряжения на ячейке. Представленная модель позволяет точно описывать динамические характеристики подводных разрядов на основе физико-химических свойств раствора, что позволяет предсказывать поведение разряда при использовании растворов с заданными свойствами.
\end{abstract}

Ключевые слова: подводный электрический разряд, динамическая модель, электропроводность.

DOI: 10.21883/PJTF.2021.19.51512.18882

Различные комбинации электрического разряда и жидкости представляют интерес в сфере очистки и стерилизации водных сред, при модифицировании полимеров, синтезе наноструктур, что отражено в обзорах последних лет [1-3]. Помещение зоны плазмы в объем жидкости приводит к ускорению протекания процессов в растворе. Это представляется благоприятным для прикладных исследований данного типа плазмы. Теоретические исследования электрофизических характеристик подводной плазмы позволили представить механизм формирования/развития подводных разрядов [4-6]. В ряде работ представлены модели подводной плазмы, основанные на электрических характеристиках разряда, которые дают подробную информацию об образовании парогазового пузыря, в котором возникает плазма $[7,8]$. Свойства жидкости при этом не учитываются. В настоящей работе рассматривается модель подводного разряда с учетом физико-химических свойств раствора/жидкости.

Предполагается, что за время формирования газового пузыря, которое определяется химическим составом, концентрацией растворенного вещества, электропроводностью и действительным значением прикладываемого напряжения, процессы протекают не в плазме, а в объеме раствора. При схлопывании плазменного пузыря в растворе возникают конвективные потоки, вызванные акустической и ударной волнами и градиентом температуры, которые переносят продукты плазмолиза (атомы, радикалы и ионы) в основной объем раствора. Это оказывает влияние на физико-химические свойства раствора и свойства всей системы. Электрическая схема предлагаемой модели представлена на рис. 1, $a$. В электрическую цепь, питаемую источником переменного тока, последовательно включены балластное сопротивление и сопротивление разрядной системы, которое включает в себя сопротивление объема раствора, и параллельно соединенные сопротивления плазмы и пленки раствора.

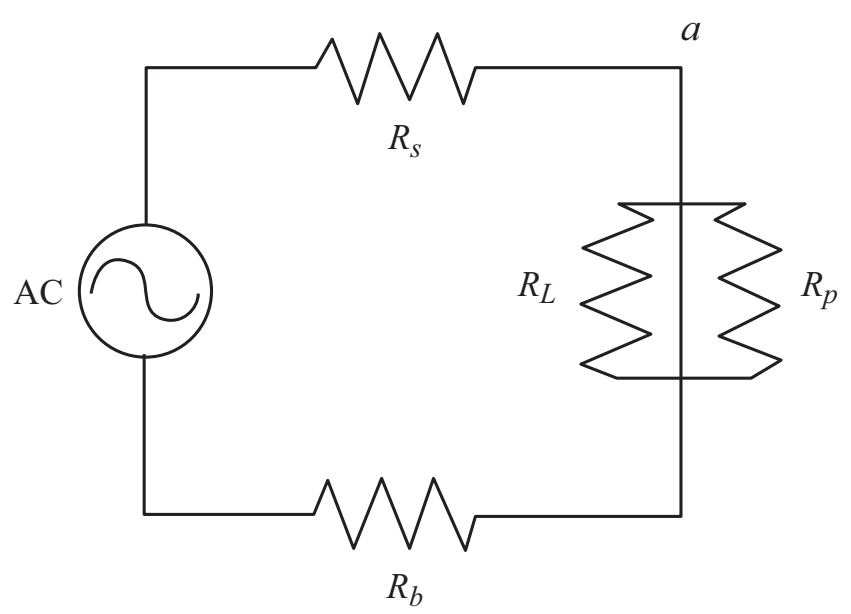

$b$

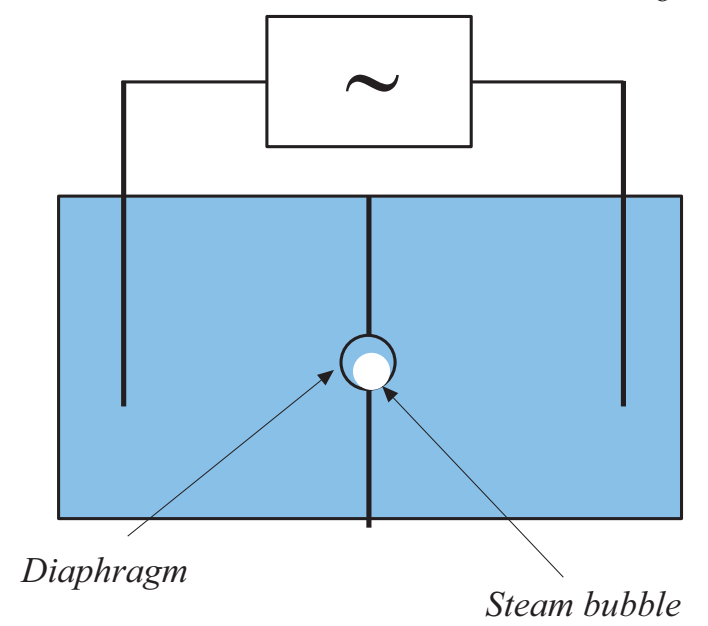

Рис. 1. Электрическая схема модели $(a)$ и схема устройства подводного разряда $(b) . R_{b}-$ балластное сопротивление, $R_{s}-$ сопротивление раствора, $R_{L}-$ сопротивление слоя, $R_{p}-$ сопротивление плазмы. 
$a$
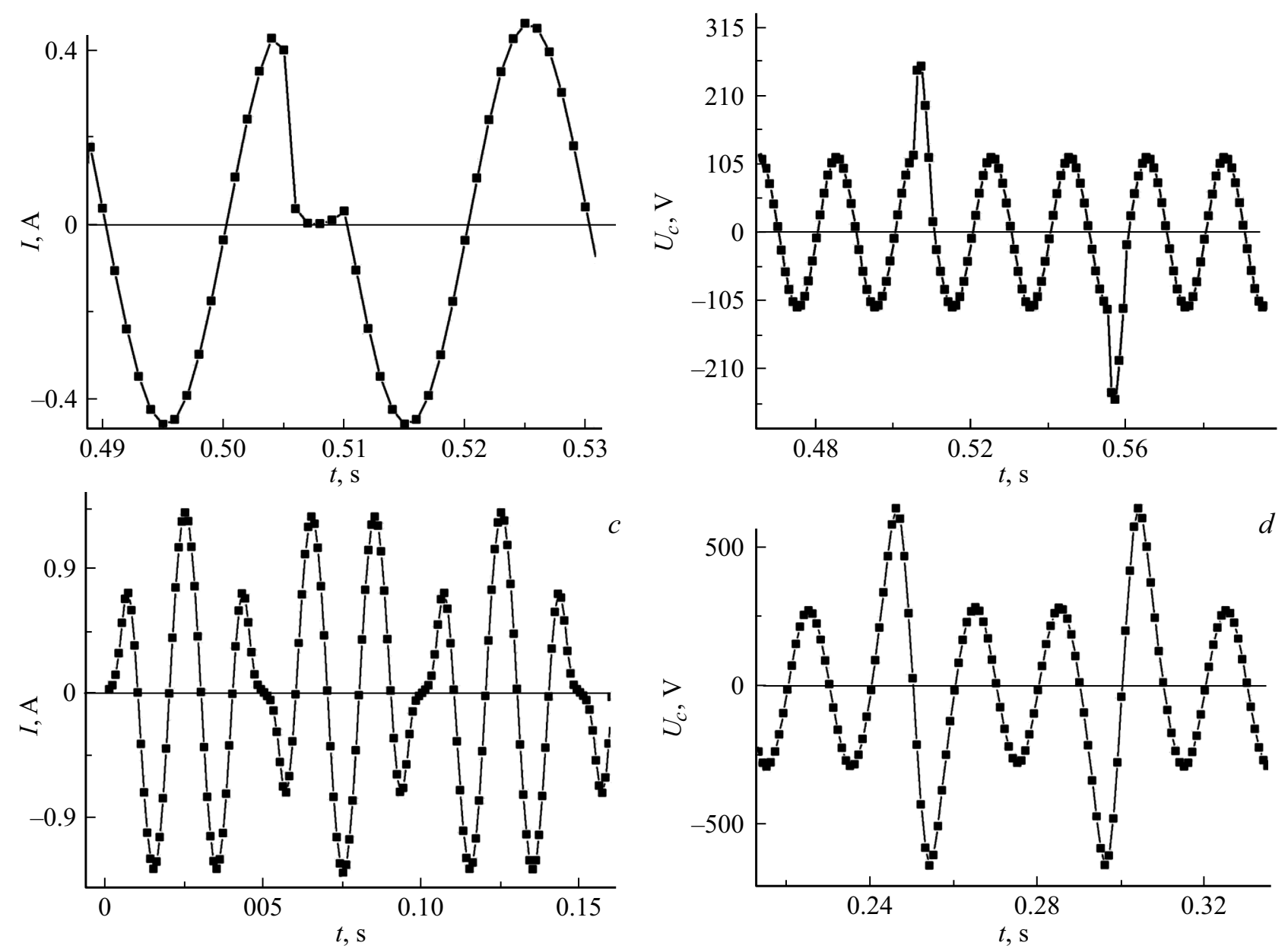

Рис. 2. Временны́е изменения тока разряда $(a, c)$ и падения напряжения на ячейке $(b, d)$, полученные при использовании сигмоидальной $(a, b)$ и гиперболической $(c, d)$ функций.

Разрядная система, включенная в электрическую цепь, содержит ячейку с раствором, разделенную на две части перегородкой/мембраной с отверстием (диафрагмой). Через диафрагму течет ток электролиза и в ней же формируется газовый пузырь (рис. $1, b)$.

Напряжение прикладывается к нагрузке, которая состоит из балластного сопротивления и комплексного сопротивления ячейки (последовательное соединение сопротивления раствора и разрядного промежутка). Балластное сопротивление является величиной постоянной, так же как и действительное значение прикладываемого напряжения. Однако величина комплексного сопротивления ячейки будет меняться. Об этом свидетельствуют экспериментальные данные для отношения $I / U$ [5]. Ток в данной цепи будет определяться соотношением

$$
I=\frac{\varepsilon_{t o t a l}}{R_{b}+R_{c}}
$$

Здесь $\varepsilon_{\text {total }}$ - прикладываемое напряжение, $R_{b}$ - балластное сопротивление, $R_{c}$ - сопротивление ячейки.

Напряжение, прикладываемое к разрядному промежутку, будет определяться разницей между приклады- ваемым напряжением и падением напряжения на балластном сопротивлении

$$
U_{c}=\varepsilon_{t o t a l}-I R_{b}
$$

Предположим, что толщина проводящего слоя $\delta$ в диафрагме может меняться в определенных пределах $0<\delta<d$, где $d-$ диаметр диафрагмы. Таким образом, в момент отсутствия пузырька отверстие (диафрагма) заполнено раствором электролита, проводимость максимальна и определяется электропроводностью раствора. В том случае, когда размер пузыря достигает максимума, толщина проводящего слоя в пределе будет нулевой. На основании этого можно задать зависимость проводимости от толщины проводящего слоя $\lambda=f(\delta)$. Для математического описания модели были выбраны нелинейные аппроксимации пакета Origin. Методом итераций были отобраны функции, дающие кривую с насыщением для зависимости $\lambda(\delta)$ и зависимости $I(t)$ и $U(t)$, согласующиеся с экспериментальными осциллограммами. Таким условиям отвечают только две функ- 
ции: сигмоидальная

$$
\lambda=\frac{1}{1+e^{-\delta}}
$$

и гиперболическая

$$
\lambda=\frac{e^{\delta}-e^{-\delta}}{e^{\delta}+e^{-\delta}} .
$$

На основе данных видеонаблюдений были получены времена образования и гибели газового пузыря порядка 0.1-0.2 s. Если предположить, что процессы будут протекать непрерывно, то их можно описать периодической зависимостью с характерной частотой $5-10 \mathrm{~Hz}$ и вывести временны́е зависимости.

Выражая $R$ через $\lambda=f(\delta)$ и подставляя в уравнения для тока и напряжения, мы рассчитали функции $I=f(t)$ и $U=f(t)$ с использованием пакета Origin. Результаты моделирования представлены графически (рис. 2).

Анализ полученных результатов показывает, что сигмоидальная зависимость $\lambda=f(\delta)$ позволяет получить динамические характеристики тока и напряжения во времени, полностью согласующиеся с экспериментом [9]. Гиперболическая функция более „плавно“ следит за изменениями толщины проводящего слоя. В связи с этим переходы между состояниями системы (режимы горения разряда) происходят более „гладко“ и длительно.

Таким образом, модель позволяет четко описывать динамические свойства подводного разряда. Исходные положения данной модели не используют эмпирические данные для $I=f(t)$ и $U=f(t)$, но базируются на экспериментальных оценках времен образования и гибели газового пузырька. Следовательно, полученная модель полуэмпирическая и подтверждает гипотезу о том, что динамические особенности подводных разрядов определяются физико-химическими свойствами раствора.

\section{Конфликт интересов}

Автор заявляет, что у нее нет конфликта интересов.

\section{Список литературы}

[1] S. Horikoshi, N. Serpone, RSC Adv., 7 (75), 47196 (2017). DOI: 10.1039/C7RA09600C

[2] F. Rezaei, P. Vanraes, A. Nikiforov, R. Morent, N. De Geyter, Materials, 12 (17), 2751 (2019). DOI: 10.3390/ma12172751

[3] S. Perinban, V. Orsat, V. Raghavan, Compr. Rev. Food Sci. Food Saf., 18 (6), 1985 (2019). DOI: $10.1111 / 1541-4337.12503$

[4] M. Monte, F. de Baerdemaeker, C. Leys, A.I. Maximov, Czech. J. Phys., 52 (Suppl. D), 724 (2002).

[5] A.I. Maximov, Contrib. Plasma Phys., 47 (1-2), 111 (2007). DOI: $10.1002 /$ ctpp.200710016

[6] A.V. Khlyustova, A.M. Manakhov, A.I. Maksimov, Surf. Eng. Appl. Electrochem., 45 (6), 485 (2009).

DOI: $10.3103 / \mathrm{S} 1068375509060088$
[7] V.T. Gurovich, A. Grinenko, Y.E. Krasik, J. Felsteiner, Phys. Rev. E, 69 (3), 036402 (2004). DOI: 10.1103/PhysRevE.69.036402

[8] X. Lu, J. Appl. Phys., 102 (6), 063302 (2007). DOI: $10.1063 / 1.2783848$

[9] A. Khlyustova, N. Sirotkin, O. Evdokimova, V. Prisiazhnyi, V. Titov, J. Electrostat., 96, 76 (2018). DOI: $10.1016 /$ j.elstat.2018.10.002 